\title{
Evaluation of Building Integrated Photovoltaic Systems' Potential in the Industrial Sector: Case Study of Oinofyta-Viotia Zone, Greece
}

\author{
Georgios Vokas ${ }^{1}$, Panagiotis Klironomos ${ }^{2}$ and John Kaldellis ${ }^{2}$ \\ 1. Lab of Power Electronics, Department of Electronics Engineering, Technological Educational Institute of Piraeus, Athens 12201, \\ Greece \\ 2. Lab of Soft Energy Applications \& Environmental Protection, Technological Educational Institute of Piraeus, Athens 12201, \\ Greece
}

Received: January 06, 2013 / Accepted: April 09, 2013 / Published: December 31, 2013.

\begin{abstract}
The aim of this paper is to propose a flexible and accurate methodology for the evaluation of the BIPV (building integrated photovoltaic) potential on industrial building roofs. The use of more realistic and case specific data obtained by accurate technical on-site audits is proved to be of significant importance in the reliability of the proposed methodology results. Moreover, the most recent PV market information is used, considering however that this factor is rapidly changing during the last years, owed to the vast growth of the PV sector. To this end, emphasis is given on the country of Greece, where besides the fact that there is an increase of PV installations; no progress has been met in the use of BIPV systems in the industrial sector, opposite to the situation met in other EU countries. Acknowledging the above, the proposed methodology is currently applied so as to evaluate the BIPV potential of a large industrial zone close to the Greek capital, Athens. The results of this study can be used by both other researchers, for similar evaluations, and energy policy makers, to support the clean energy production concept on the basis of BIPV systems in industrial areas.
\end{abstract}

Key words: BIPV, feed-in-tariff, greenhouse gas emissions, renewable energy sources, roof area potential, solar energy, technical audits.

\section{Introduction}

In Europe, the sector of PVs (photovoltaics) and renewable energy technologies and applications is growing at a much faster pace than the rest of the economy. In fact, it is this growth that along with the continuous rise in oil prices have led to the revision of energy policy in Europe and the incorporation of RES (renewable energy sources) in the fuel mix of electricity generation. In this context, promotion of electricity produced from RES in the electricity market of each European country has also been legislated by

Corresponding author: John Kaldellis, professor, research fields: renewable energy applications, hybrid energy systems, energy storage and environmental technology-atmospheric pollution. E-mail: jkald@teipir.gr. the EU directive 2001/77/EC [1]. Taking into account global economic growth and environmental pollution issues, the necessity of finding a substitute to replace fossil fuels has increased the importance of PV systems as a long-term, environmentally friendly and reliable energy technology [2]. In Greece, the three laws (i.e., 3468/06, 3734/09 and 3851/10) and the JMC (joint ministerial decree) concerning the programme for small rooftop PV installations aim to activate the responsible ministries in helping the Greek BIPV (building integrated photovoltaic) market to keep up with the development of the corresponding European market. Actually, BIPVs are one of the fastest growing segments of the PV industry and actions towards its further growth are thought to be of primary importance. 


\section{Position of the Problem}

In recent decades, the increase of energy demand worldwide, in combination with environmental degradation issues, have raised major concerns among energy scientists and policy makers regarding the adverse effects of energy use [3]. The PV industry is expected to focus on BIPV systems in the near future, because in the last few years energy consumption in the building sector has presented increasing tendencies [4]. Almost $40 \%$ of the electricity consumption in Europe originates from buildings, particularly for construction and maintenance and most of all for operation. If BIPV systems are integrated into all of these buildings there will be significant energy consumption conservation and carbon dioxide emissions will be reduced [5]. The Greek industrial buildings are according to the Greek Ministry of Environment, Energy \& Climate Change a major electricity consumer with approximately $25.5 \%$ of the total electricity consumption in Greece during 2011. The BIPV systems have the potential to become a major source of renewable energy in the urban environment because they can be integrated in both residential and industrial buildings [6]. Nevertheless, BIPV technology implementation is also new in Greece and many technicians and building owners have not yet become familiar with this evolution in PV technology. On the other hand, it should be noted that this PV-based application can be easily implemented in the industrial building sector and thus could also contribute significantly in the electricity generation of the country.

\section{Proposed Solution}

BIPV systems are used not only to generate electricity from the sun, but also as part of the building structure such as roofs, facades, shades, etc. [7]. BIPV systems have the major benefit that they are one of the most low-polluting energy sources in the world and regardless of the relatively high capital cost, they can provide a reliable solution for the supply of electricity in existing or planned buildings, either being grid connected or not. BIPV systems produce electrical power close to where energy is used and therefore losses associated with transmission and distribution of electricity generation are avoided. However, the main advantage of BIPV systems over non-integrated PVs is that they do not need extra land for their installation. Moreover, they can be used as roofing tiles, directly replacing traditional pitched roof materials, while they can also be placed on low-sloped roofs in some climates. In addition, a BIPV system can be placed as an external shading device containing PV cells [8]. Furthermore, since BIPV systems are an integral part of the building's design, they normally appear to be more aesthetically appealing than other solar technological options, while they are also ideal for producing clean energy due to the fact that they do not produce carbon dioxide emissions while generating electricity. They are easy and fast to install and are also determined by low maintenance costs and the ability to produce electricity within the urban built environment. In this context, it must also be noted that PVs have been receiving, for almost a decade now, considerable financial and regulatory support that still persists in many EU countries [9]. As a result, and taking also into account the constant technological evolution met in the field (new materials, innovative manufacturing techniques, BIPV solutions, etc.), there is a general expectation that in the next decades PVs will increasingly contribute to the electricity generation fuel mix, allowing the respective costs to fall [10]. Finally, what is also important to note concerning BIPV applications is that not only can they reduce participation of conventional energy sources, but they can also offset the "peak" electricity generation from coal and oil and the emissions from diesel generators [11].

\section{Solution Methodology}

Several researches concerning the potential of BIPV systems' implementation in the building sector have been conducted in other countries but not in 
Greece. Different methodologies and assumptions have been adopted in order to estimate the useful roof area potential of the buildings and the potential benefits from the BIPV systems' implementation. Many of these studies rely on available statistical data concerning the building sector, obtained by the national authorities of each country. The IEA (International Energy Agency) PVPS (PV power systems) program conducted a research (Task 7) for 21 member-countries focusing on BIPV systems and their potential. The methodology used in this research, in order to estimate the roof and facade area available, is based on ground floor surface area extrapolated from U.S. figures, which are then transformed in roof and facade surface area data using a simple rule of thumb: "For every square meter of building ground floor area, there are on average $0.4 \mathrm{~m}^{2}$ of rooftop area and $0.15 \mathrm{~m}^{2}$ on facade area with good BIPV potential" [12]. Kjellsson, in order to investigate the potential of BIPV in Sweden, proposed a methodology which considers the theoretical maximum use of all possible areas of building envelopes as appropriate for PV installations. The buildings of Sweden were divided into six main categories: single and two family dwellings, multifamily dwellings, non residential premises, industry, agricultural buildings and vacancy buildings. Various statistical data concerning these categories were obtained from the Statistics Authority of Sweden (SCB: Statistiska Centralbyrån) but since there was no statistical data concerning areas of the building envelope, tilt of the roofs and orientations, several assumptions were made [13]. Next, the CETC-V (CANMET Energy Technology Centre-Varennes) in Canada agreed with the methodology (and adopted the usage of the simple rule of thumb) that IEA adopted for the estimation of the potential of BIPV systems but instead of using extrapolated data from U.S. figures they used statistical data of floor areas concerning residential, commercial and institutional buildings. Finally, a multi criteria formula proposed to calculate the electricity generation from the BIPV systems and a formula for the calculation of greenhouse gas emissions are presented in Refs. [14, 15]. Opposite to the above, in Greece, there is no detailed statistical data concerning the industrial building sector. As a result, this research tries to evaluate the potential of BIPV systems in the industrial building sector of Greece for the first time, with the current study focusing on the industrial zone of Oinofyta-Viotia, close to the broader area of the Greek capital, Athens.

As already implied, statistical data concerning the surface area of the roofs of the industrial buildings as well as orientations, type of construction, shading and roof tilt angles are not available in Greece. The only available statistical data that can be obtained by the Hellenic Statistical Authority is the number of industrial buildings in the area under investigation. As a result, the methodology is based on data collected from a representative sample of 30 industrial building audits (which correspond to $13 \%$ of the whole industrial building stock) that was performed in the industrial zone of Oinofyta-Viotia for a considerable time period during October-December 2010 and from statistical data obtained from the Hellenic Statistical Authority. The sample of the 30 industrial buildings where audits were conducted, out of a total of 231 (Table 1), was selected so as to capture the entire area of the industrial zone of Oinofyta-Viotia (Fig. 1) and thus produce the most valid results possible.

Moreover, for the industrial building audits, hi-tech electronic equipment was used such as a Garmin GPS Navigator and a Digi-tech compass for obtaining each building's coordinates and orientation respectively. In addition, the average available roof area potential was estimated with Google Earth ${ }^{\mathrm{TM}}$ computer software using the coordinates of the buildings from the building audits.

Besides, the type of construction, the roof tilt angle, the roof competing uses and the shading of each industrial building were also estimated from visual, onsite inspection during the audits (Figs. 2 and 3). 
Table 1 Building names and total roof surface area of the chosen sample.

\begin{tabular}{lr}
\hline Building name & Roof surface area $\left(\mathrm{m}^{2}\right)$ \\
\hline Fourlis & 13,480 \\
Buffalo Plast Minoglou & 2,645 \\
Ravenna & 1,400 \\
Konstantakatos Bros & 9,700 \\
Makrinakis Eutixis & 2,520 \\
Sanitas-Sarantis & 14,118 \\
Eurotrade S.A & 3,100 \\
Sidma S.A & 11,000 \\
Pepsico IVI & 15,850 \\
Isomat & 1,604 \\
Atlas Stahl & 4,870 \\
LPS (logistics packing solutions) & 3,822 \\
Berling & 2,895 \\
Orphee Beinoglou & 5,718 \\
Anthemidis & 6,000 \\
Xountoumadis & 1,200 \\
Plastona & 4,400 \\
Acmon Systems S.A & 2,500 \\
Cablel & 6,384 \\
Telecables S.A & 9,591 \\
Vasilias & 3,481 \\
Zakos & 2,886 \\
Cardico & 16,600 \\
Alapis & 6,000 \\
Global Maritime Agency S.A & 1,144 \\
Europa & 3,712 \\
Attiki Kinisi Logistics & 11,877 \\
Agroefodia & 950 \\
Vogiatzoglou Systems & 5,870 \\
Veltro & \\
Profilco & 24,000 \\
\hline
\end{tabular}

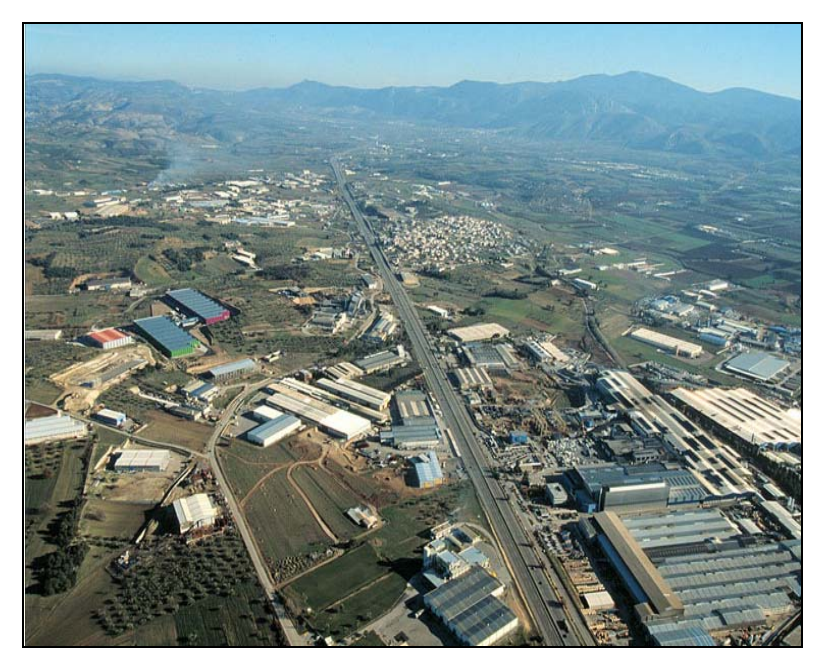

Fig. 1 Photomap of industrial zone of Oinofyta-Viotia (source: www.greekscapes.gr).

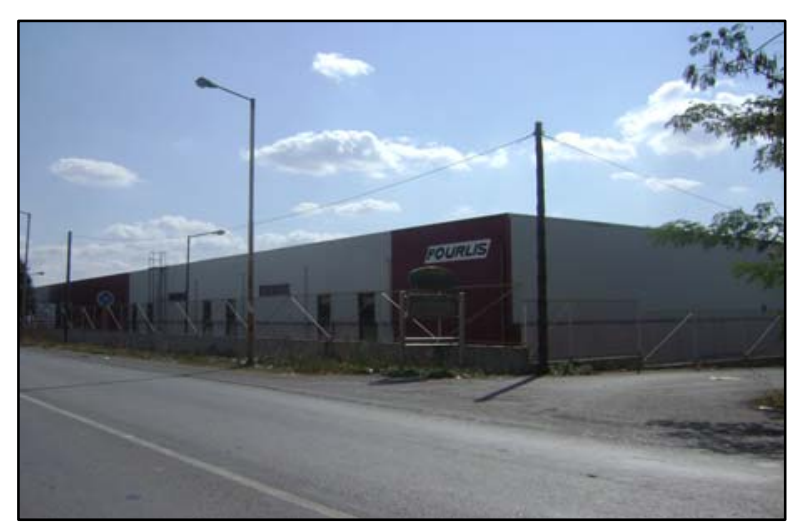

Fig. 2 Real view of a building (collected during building audit).

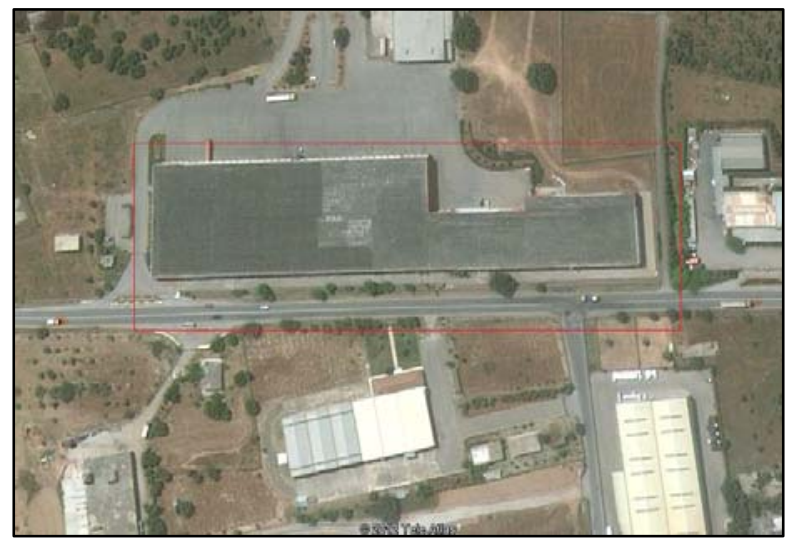

Fig. 3 View of a building from Google Earth ${ }^{\mathrm{TM}}$.

Furthermore, the solar irradiation of Oinofyta-Viotia for each PV tilt angle was obtained from the PVGIS (photovoltaic geographical information system) software. To this end, the statistical analysis of the findings-data from the industrial building audits designated three categories of buildings in terms of roof tilt angle: (1) industrial buildings with roof tilt angle of $0^{\circ}$; (2) industrial buildings with roof tilt angle of $15^{\circ}$; and (3) industrial buildings with roof tilt angle of $20^{\circ}$. The total average useful roof area potential $\left(\mathrm{m}^{2}\right)$ per building $\left(A_{0^{\circ}}, A_{15^{\circ}}, A_{20^{\circ}}\right)$ was estimated using different reduction coefficients for each roof tilt angle $\left(0^{\circ}, 15^{\circ}, 20^{\circ}\right)$. In this context, to estimate the average useful area potential, the average available roof surface $\left(\mathrm{m}^{2}\right)$ area $\left(A_{1}, A_{2}, A_{3}\right)$ per industrial building category should underlie significant reductions due to legislation, roof tilt angle, PV shading and roof competing uses. The reduction coefficients are: (1) the PS (perimeter space) for maintenance actions in the PV installations 
(is calculated 0.97); (2) in order to avoid shading $\left(S_{P V}\right)$ between PV panels a significant space should exist (the corresponding coefficient is calculated 0.52 for flat-roof industrial buildings and 1 for industrial buildings with roof tilt angle of $15^{\circ}-20^{\circ}$ ); and (3) the RCU (roof competing uses) coefficient was estimated 0.80 . As a result, the average useful roof surface area per industrial building category was calculated from the following equations:

$$
\begin{gathered}
A_{0}=A_{1} \cdot P S \cdot S_{P V} \cdot R C U \\
A_{15}=A_{2} \cdot P S \cdot S_{P V} \cdot R C U \\
A_{20}=A_{3} \cdot P S \cdot S_{P V} \cdot R C U
\end{gathered}
$$

In order to estimate the expected electricity generation $\left(E_{0^{\circ}}, E_{15^{\circ}}, E_{20^{\circ}}\right)$, the PVGIS software was used to obtain the global irradiation $\left(I_{31^{\circ}}, I_{15^{\circ}}, I_{20^{\circ}}\right)$ per square meter received by the modules $\left(\mathrm{kWh} / \mathrm{m}^{2}\right)$, especially for the industrial zone of Oinofyta-Viotia. Note however that although the optimum PV tilt angle [16] for this area was calculated at $31^{\circ}$, this can only be applied in industrial buildings with flat roof due to legislation constraints, since in the other two building categories the PV panels will be installed at a PV tilt angle of $15^{\circ}$ and of $20^{\circ}$, respectively.

$$
\begin{aligned}
& E_{0^{\circ}}=A_{0^{\circ}} \cdot P \text { Ppane }_{\text {ff }} \cdot P \text { Vsystem } e_{\text {fff }} \cdot Y \cdot I_{\text {Opt.Angle }} \\
& E_{15^{\circ}}=A_{15^{\circ}} \cdot \text { PVpanel }_{\text {eff }} \cdot P \text { Psystem }_{\text {eff }} \cdot Y \cdot I_{15^{\circ}} \\
& E_{20^{\circ}}=A_{20^{\circ}} \cdot P \text { Ppanel }_{\text {eff }} \cdot \text { PVsystem }_{\text {eff }} \cdot Y \cdot I_{20^{\circ}}
\end{aligned}
$$

where:

$A_{0^{\circ}}, A_{15^{\circ}}, A_{20^{\circ}}$ is the average total useful roof surface area per industrial building category;

PVpanel $_{\text {eff }}$ is the PV panel efficiency (it is currently taken $15 \%$ for a mono-crystalline PV panel);

PVsystem $_{\text {eff }}$ is the PV system performance ratio (it is currently taken 0.80 );

$Y$ is solar yield "the relative value of solar energy irradiated on a given surface in $\%$ of the maximum annual solar input of the best oriented surface" (it is currently taken 0.90 for a rooftop in Oinofyta-Viotia) [17];

$I_{31^{\circ}}, I_{15^{\circ}}, I_{20^{\circ}}$ is the annual solar irradiation for Oinofyta-Viotia for PV tilt angles $\left(31^{\circ}, 15^{\circ}, 20^{\circ}\right)$.

In order to calculate the potential $\mathrm{PV}$ installed capacity $\left(P_{0^{\circ}}, P_{15^{\circ}}, P_{20^{\circ}}\right)$ per each building category one may use the following equations considering a typical PV panel with dimensions $(L \times W \times H)=1,680 \mathrm{~mm} \times$ $990 \mathrm{~mm} \times 50 \mathrm{~mm}($ SOLARWATT M250-60AC $\sim 250$ $\mathrm{W}_{\mathrm{p}}$ ), assuming also that for a PV system installation of $1 \mathrm{~kW}_{\mathrm{p}}$ the roof surface area that is required is approximately $6.8 \mathrm{~m}^{2}$ :

$$
\begin{gathered}
P_{0^{\circ}}=\frac{A_{0} \cdot 1 \mathrm{~kW}}{6.8 \mathrm{~m}^{2}} \\
P_{15^{\circ}}=\frac{A_{15} \cdot 1 \mathrm{~kW}}{6.8 \mathrm{~m}^{2}} \\
P_{20^{\circ}}=\frac{A_{20} \cdot 1 \mathrm{~kW}}{6.8 \mathrm{~m}^{2}}
\end{gathered}
$$

Finally, in order to calculate the total useful roof surface area, the total potential electricity generation of BIPV systems and the total potential PV installed capacity for the 231 industrial buildings in Oinofyta-Viotia, the following equations may be used:

$$
\begin{aligned}
A_{\text {TOTAL }} & =A_{n=30} \cdot 231 \\
E_{\text {TOTAL }} & =E_{n=30} \cdot 231 \\
P_{\text {TOTAL }} & =P_{n=30} \cdot 231
\end{aligned}
$$

where:

$$
A_{n=30}=\left(7 \cdot A_{0^{\circ}}+19 \cdot A_{15^{\circ}}+4 \cdot A_{20^{\circ}}\right) / 30 \text { is the total }
$$
average useful roof surface area per building;

$$
P_{n=30}=\left(7 \cdot P_{0^{\circ}}+19 \cdot P_{15^{\circ}}+4 \cdot P_{20^{\circ}}\right) / 30 \text { is the total }
$$
average $\mathrm{PV}$ installed capacity per building;

$E_{n=30}=\left(7 \cdot E_{0^{\circ}}+19 \cdot E_{15^{\circ}}+4 \cdot E_{20^{\circ}}\right) / 30$ is the total average electricity generation per building.

Excluding the last three years of economic recession, the electricity generation in Greece showed a significant growth since 1980. According to statistical data for 2012 from the Greek PPC (Public Power Corporation), lignite remains [15] the most important fuel for electricity generation in Greece, representing $46.3 \%$ of total generation. Oil has historically been a very important fuel (used almost exclusively for electricity generation in the Greek islands) representing $8.31 \%$ of the total generation. At the same time, in the mainland system, oil is gradually being replaced by natural gas that now represents almost $23 \%$ of the total annual electricity generation. Besides, $6.65 \%$ of the total electricity generation corresponds to imports from interconnections with other countries. Finally, the 
contribution of RES in the Greek electricity production is $7.02 \%$, while large hydro power stations contribute with $8.54 \%$. In the following, one may calculate the emissions $\left(\mathrm{CO}_{2}, \mathrm{SO}_{2}, \mathrm{NO}_{\mathrm{x}}\right)$ avoided [18] due to the BIPV in the area under investigation, taking into account the corresponding national fuel mix. Actually, Table 2 presents the official electricity generation emission coefficients by fuel type.

On the other hand, Fig. 4 demonstrates the time evolution of the average turn-key cost of a typical 500 $\mathrm{kW}_{\mathrm{p}}$ BIPV system in Greece until 2012, along with three scenarios concerning the development of the turn-key cost in the next two years. Scenario 1 (blue colour), considers a constant turn-key cost for the next two years, while Scenarios 2 (green colour) and 3 (red colour) assume a decrease of the turn-key cost by $5 \%$ and $10 \%$ respectively (most probable scenario to occur due to the ongoing deep economic recession and financial instability in Greece). The equipment (panels, inverters, mounting system, cables, transformers) used for this cost analysis is of European origin.

The investment cost for implementing BIPV systems in industrial buildings in Oinofyta-Viotia (considering also an annual maintenance cost of $10,000 € / 500 \mathrm{~kW}_{\mathrm{p}}$ ) is presented in Table 3. In this Table, the potential income from the electricity generation by BIPV systems per industrial building is presented according to the variation of FIT for PV-based electricity generation. As a result, the simple pay back period for a BIPV implementation with installed capacity of 545 $\mathrm{kW}_{\mathrm{p}}$ is approximately 7-9 years, depending on the implementation scenario (Table 4) [19, 20].

\section{Results and Discussion}

In the following, the proposed analysis is applied for the industrial area of Oinofyta-Viotia. More precisely the building audits' results are presented in Figs. 5-8.

According to the building audits that have been carried out in the industrial zone of Oinofyta, for all the industrial buildings there was no evidence of shading from nearby buildings, obstacles, trees, etc.. So, no shading losses have been considered.
Table 2 Emission coefficients for electricity generation by

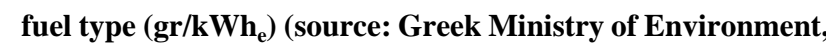
Energy \& Climate Change).

\begin{tabular}{llll}
\hline Fuel type & $\mathrm{CO}_{2}$ & $\mathrm{SO}_{2}$ & $\mathrm{NO}_{\mathrm{x}}$ \\
\hline Lignite & 1,100 & 11.8 & 4.3 \\
Oil & 750 & 1.5 & 2.9 \\
Nat. gas & 450 & - & 1 \\
\hline
\end{tabular}

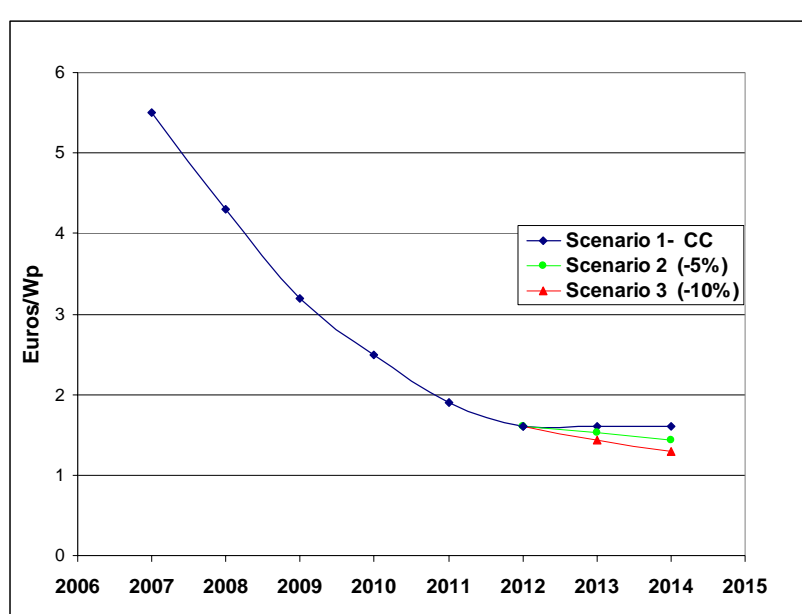

Fig. 4 Turn-key average cost of a $500 \mathrm{~kW}_{\mathrm{p}}$ system in Greece.

Table 3 Potential investment income (k€) from the electricity generation of BIPV systems per industrial building.

\begin{tabular}{lllrrrr}
\hline Year & Month & $\begin{array}{l}\text { FIT } \\
(€ / \mathrm{MWh})\end{array}$ & $\begin{array}{l}\text { Income } \\
(\mathrm{k} €)\end{array}$ & \multicolumn{2}{c}{ Investment cost $(\mathrm{k} €)$} \\
\hline 2012 & August & 180 & 115 & 872 & 872 & 872 \\
\hline 2013 & February & 171.9 & 110 & 872 & 828 & 785 \\
2013 & August & 164.16 & 104 & & & \\
\hline 2014 & February & 156.78 & 99 & 872 & 785 & 703 \\
2014 & August & 149.72 & 94 & & & \\
\hline & & & & Sc. 1 & Sc. 2 & Sc. 3 \\
\hline
\end{tabular}

Table 4 Potential simple payback period (years) depending on the implementation scenario.

\begin{tabular}{llllll}
\hline Year & Month & $\begin{array}{l}\text { FIT } \\
(€ / \mathrm{MWh})\end{array}$ & SPBP & & \\
\hline 2012 & August & 180 & 7.6 & & \\
2013 & February & 171.9 & 8.0 & 7.6 & 7.2 \\
2013 & August & 164.16 & 8.4 & 8.0 & 7.6 \\
2014 & February & 156.78 & 8.8 & 7.9 & 7.1 \\
2014 & August & 149.72 & 9 & 8 & 7 \\
\cline { 3 - 5 } & & & Sc. 1 & Sc. 2 & Sc. 3 \\
\hline
\end{tabular}

Further results from the technical audits showed that $76.6 \%$ of the buildings have a roof tilt angle of $15^{\circ}-20^{\circ}$ and $23.3 \%$ of the buildings have a roof tilt angle of $0^{\circ}$, as shown in Fig. 5. 


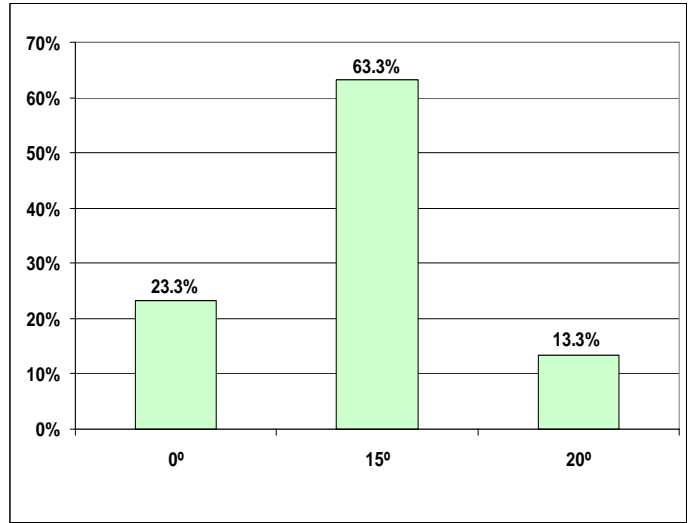

Fig. 5 Percentage of buildings per roof tilt angle.

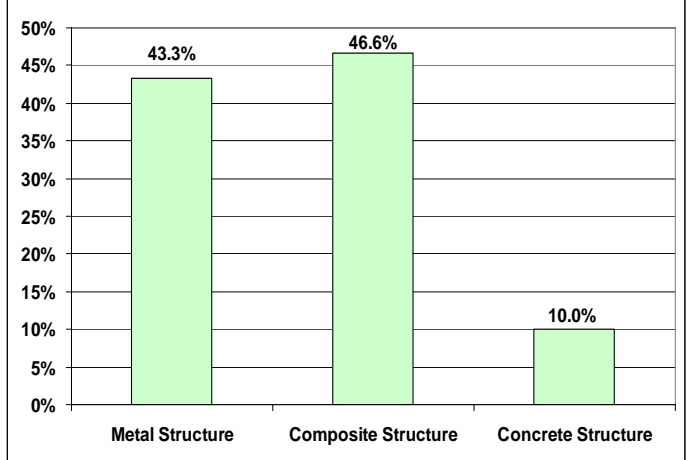

Fig. 6 Percentage of buildings per type of construction.

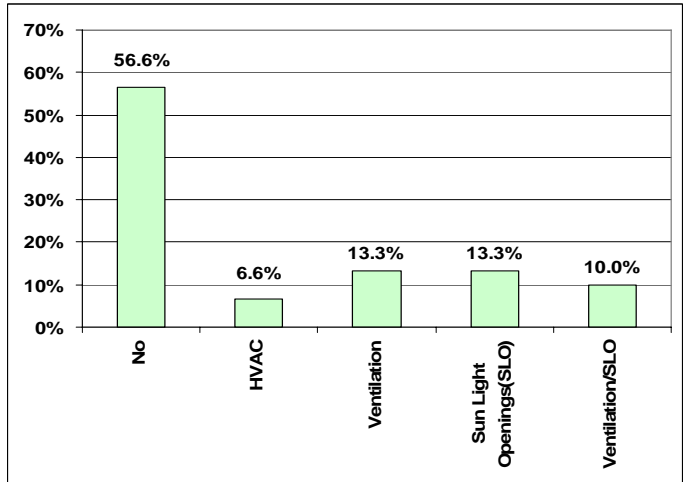

Fig. 7 Percentage of buildings per roof competing uses.

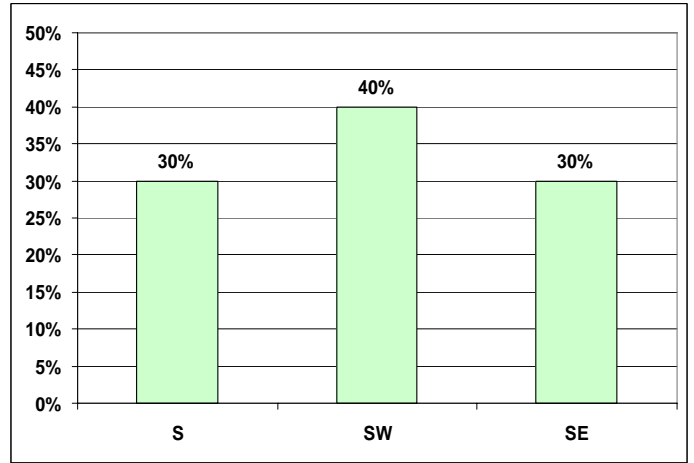

Fig. 8 Percentage of buildings per building orientation.
Almost $90 \%$ of the building structure is made from metal or composite materials, as shown in Fig. 6, while only $10 \%$ is made from concrete. As a result, the static load of a light PV installation is proven to be bearable by any structure examined.

As shown in Fig. 7, more than half of the audited buildings have a completely clear roof surface. However, there are many roof competing uses observed such as sun light openings, ventilation and HVAC units.

Besides, most of the audited buildings with inclination had quite good orientation, as shown in Fig. 8. The low tilt of the panels on these roofs $\left(10^{\circ}\right.$ and $\left.15^{\circ}\right)$ helps keeping the losses, due to non-optimal orientation (SE, SW), low.

Subsequently, the industrial buildings with roof tilt angle of $0^{\circ}$ have an average available roof surface area of $6,709 \mathrm{~m}^{2}$, the industrial buildings with roof tilt angle of $15^{\circ}$ have an average available roof surface area of $4,134 \mathrm{~m}^{2}$ and the industrial buildings with roof tilt angle of $20^{\circ}$ have an average available roof surface area of $4,438 \mathrm{~m}^{2}$. However, to estimate the total average useful roof surface area potential, this average available roof surface area should underlie significant reductions due to legislation constraints, roof tilt angle, PV shading, roof competing uses and roof loads. After the appropriate reductions in the average available roof surface area for each building category, the total average useful roof surface area has been estimated as $3,394 \mathrm{~m}^{2}$ per industrial building. Accordingly, based on data from the most recent building stock inventory of Greece, the number of industrial buildings in Oinofyta-Viotia is as already seen 231 . This means that the total useful roof surface area potential of industrial buildings in Oinofyta-Viotia is approximately 860,000 $\mathrm{m}^{2}$ or $0.86 \mathrm{~km}^{2}$. Meanwhile, the cumulative installed capacity of PV systems in Greece in 2012 was 1,333.4 $\mathrm{MW}_{\mathrm{p}}$ (grid-connected systems) with a provision to reach 2,200 $\mathrm{MW}_{\mathrm{p}}$ in 2020.

Applying analytical calculations, it is estimated that BIPV systems installed in the industrial buildings of 
Oinofyta-Viotia could contribute with a total potential installed capacity of $126 \mathrm{MW}_{\mathrm{p}}$. This corresponds to approximately $545 \mathrm{~kW}_{\mathrm{p}}$ of installed capacity per average industrial building. The investment cost for implementing BIPV systems in industrial buildings is estimated (Table 3) at approximately $703-872 \mathrm{k} €$ /industrial building and as a result the simple pay back period is estimated to vary between 7 and 9 years.

Each industrial building with BIPV system can produce on average electricity which is equal to 694 $\mathrm{MWh} / \mathrm{year}$. Thus, the total expected electricity generation from BIPV systems installed on the roofs of the industrial buildings in Oinofyta-Viotia is estimated equal to $0.106 \mathrm{TWh}$, while the total electricity generation in Greece during 2010 was $51.50 \mathrm{TWh}$.

On the basis of the above analysis, the implementation of BIPV systems in industrial buildings in Oinofyta-Viotia could contribute approximately $0.21 \%$ to the total electricity generation in Greece. Moreover, it has been estimated that there will be a reduction of $108,000 \mathrm{t}$ of $\mathrm{CO}_{2}$ emissions which correspond to the $\mathrm{CO}_{2}$ absorbance of $8,325,000$ trees, $896 \mathrm{t}$ of $\mathrm{SO}_{2}$ emissions and $376.2 \mathrm{t}$ of $\mathrm{NO}_{\mathrm{x}}$ emissions if BIPV systems are implemented in the buildings of the industrial zone in Oinofyta-Viotia, due to the replacement of conventional fuels used for electricity generation [19].

\section{Conclusions}

This study proposes a complete methodology to evaluate the potential of BIPV systems in industrial buildings. The developed methodology is accordingly applied in Oinofyta-Viotia, taking also into consideration that in Greece there is no sufficient statistical data concerning the local building stock. As a result, a different methodology than the one implemented in other studies should be adopted for the case of Greece. In this context, an investigation was performed to evaluate the potential benefits of integrating PV systems in industrial buildings, calculate the greenhouse gas emissions' reduction and also determine whether an investment of a BIPV system in full scale is sustainable in financial terms.

According to the results obtained, the proposed methodology may equally well be applied in the other industrial zones of Greece, in order to estimate the expected benefits for the entire industrial building sector of Greece, which is a challenging domain for future research.

\section{References}

[1] J. Waldau, Photovoltaics and renewable energies in Europe, Renewable \& Sustainable Energy Reviews 11 (2007) 1414-1437.

[2] H. Ren, W. Gao, Y. Ruan, Economic optimization and sensitivity analysis of photovoltaic system in residential buildings, Renewable Energy 34 (2009) 883-889.

[3] E. Hatzigeorgiou, H. Polatidis, D. Haralambopoulos, $\mathrm{CO}_{2}$ emissions in Greece for 1990-2002: A decomposition analysis and comparison of results using Arithmetic Mean Divisia Index and Logarithmic Mean Divisia Index techniques, Energy 33 (2008) 429-499.

[4] G. Bakos, M. Soursos, N.F. Tsagas, Technoeconomic assessment of a building-integrated PV system for electrical energy saving in residential sector, Energy and Buildings 35 (2003) 757-762.

[5] L. Mercaldo, M. Addonizio, M. Noce, P. Veneri, A. Scognamiglio, C. Privato, Thin film silicon photovoltaics: Architectural perspectives and technological issues, Applied Energy 86 (10) (2009) 1836-1844.

[6] Y. Wang, W. Tian, J. Ren, L. Zhu, Q. Wang, Influence of a building's integrated-photovoltaics on heating and cooling loads, Applied Energy 83 (2006) 989-1003.

[7] B. Liu, S. Duan, T. Cai, Modeling and coordinate control of photovoltaic DC building module based BIPV system, Solar Energy 86 (2011) 482-488.

[8] J.J. Bloem, Evaluation of a PV-integrated building application in a well-controlled outdoor test environment, Building and Environment 43 (2008) 205-216.

[9] A. Papadopoulos, M. Karteris, An assessment of the Greek incentives schemes for photovoltaics, Energy Policy 73 (2009) 1945-1952.

[10] J.N. Schoen, Building-integrated PV installations in the Netherlands: Examples and operational experiences, Solar Energy 70 (2001) 467-477.

[11] Photovoltaics Bulletin, An International Newsletter, Elsevier Ltd., Jan. 2003.

[12] IEA (International Energy Agency), Country Reports on PV Systems Performance [Online], 2004, www.iea-pvps.org. 


\section{Evaluation of Building Integrated Photovoltaic Systems' Potential in the Industrial Sector: Case Study of Oinofyta-Viotia Zone, Greece}

[13] E. Kjellsson, Potential for Building Integrated Photovoltaics, Study for Sweden, Report 1: Area of Building Envelopes, report TVBH-7211, Lund Institute of Technology, Lund University, Dept. of Buildings Physics, Lund, Sweden, 1999.

[14] S. Pelland, Y. Poissant, An Evaluation of the potential of building integrated photovoltaics in Canada, CANMET Energy Technology Centres-Varennes (CETC-V), Natural Resources Canada, 2009.

[15] J.K. Kaldellis, N. Mantelis, D. Zafirakis, Evaluating the ability of Greek power stations to comply with the obligations posed by the second national allocation plan concerning carbon dioxide emissions, Fuel 90 (2011) 2884-2895.

[16] J.K. Kaldellis, D. Zafirakis, Experimental investigation of the optimum summer period photovoltaic panels' tilt angle, Energy 38 (2012) 305-314.

[17] J.K. Kaldellis, M. Kapsali, Simulating the dust effect on the energy performance of photovoltaic generators based on experimental measurements, Energy 36 (2011) 5154-5161.

[18] J.K. Kaldellis, M. Kapsali, M. Emmanouilidis, Long-term evaluation of nitrogen oxides and sulphur dioxide emissions from the Greek lignite-based electricity generation sector, Fresenius Environmental Bulletin 21 (2012) 2676-2688.

[19] P.G. Klironomos, Potential of BIPV (building integrated photovoltaic systems) in industrial buildings in Oinofyta-Viotia, M.Sc. Dissertation, Dept. Engineering and Physical Sciences, Univ. Herriot Watt-Dept. of Mechanical Engineering, TEI of Piraeus, 2012.

[20] P.G. Klironomos, G.A. Vokas, J.K. Kaldellis, Potential of BIPV (building integrated photovoltaic systems) systems: Study on the Oinofyta-Viotia industrial buildings zone, in: 8th Mediterranean Conference on Power Generation, Transmission, Distribution and Energy Conversion MedPower, 2012. 